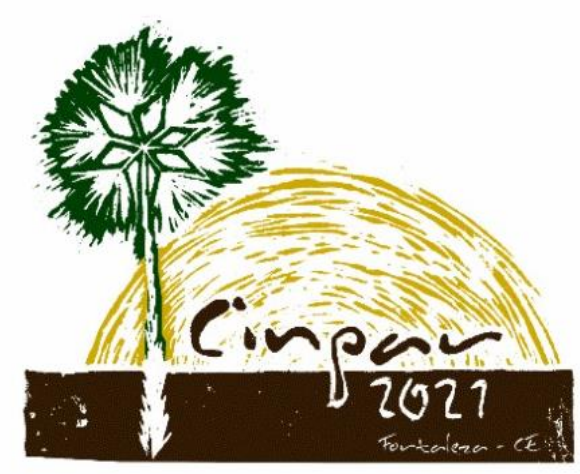

XVII Congresso Internacional sobre Patologia e

Reabilitação das Construções

XVII Congreso Internacional sobre Patología y

Rehabilitación de las Construcciones

XVII International Conference on Pathology and Constructions Rehabilitation

FORTALEZA (Brasil), 3 a 5 de junho de 2021

https://doi.org/10.4322/CINPAR.2021.116

\title{
ANÁLISE DE MANIFESTAÇÕES PATOLÓGICAS PRESENTES NAS ESCOLAS PÚBLICAS DE JABOATÃO DOS GUARARAPES-PE
}

\section{ANALYSIS OF PATHOLOGICAL MANIFESTATIONS PRESENTS AT THE PUBLIC SCHOOLS OF JABOATÃO DOS GUARARAPES- PE}

\author{
Otavio FAUSTINO ${ }^{1}$, Alexandre PORTO², Francisco MONTEIRO ${ }^{3}$ \\ ${ }^{1}$ UFPE, Recife, Brasil, otavio.faustino@ufpe.br \\ ${ }^{2}$ UNIFG, Recife, Brasil, Alexandre.porto@unifg.edu.br \\ ${ }^{3}$ UNIFG, Recife, Brasil, Francisco.monteiro@unifg.edu.br
}

\begin{abstract}
Resumo: A falta de manutenção associada a erros construtivos e o não cumprimento das normas técnicas brasileiras, contribuem para o mal desempenho das estruturas e o surgimento de diferentes manifestações patológicas. O objetivo deste trabalho foi analisar o estado de conservação das estruturas de cinco escolas públicas municipais, próximas ao mar localizadas na cidade de Jaboatão dos Guararapes/PE. As escolas estão à uma distância média de aproximadamente $658 \mathrm{~m}$ da orla marítima. Foi realizada uma inspeção visual e analisando as manifestações e suas possíveis causas patológicas, com o objetivo de fazer recomendações quanto aos cuidados e sua preservação. A Inspeção visual foi realizada "in loco" e também foram tira das várias fotos em todas as escolas, assim permitindo a identificação de diversas patologias e as prováveis causas de seu surgimento. Foram encontradas umidade excessiva em todas as escolas totalizando $47 \%$ das ocorrências dos casos, bolor $23 \%$ das ocorrências, trincas e fissuras em 4 escolas com $6 \%$, corrosão das armaduras em duas das cinco escolas com $4 \%$ e a presença de patologias adquiridas como é o caso das vegetações com $10 \%$ um grande indicador da falta de manutenção e cuidados básicos. Concluiu-se que em todas as escolas tinham algum tipo de patologia, seja por erros construtivos como é o caso do cobrimento associado a falta de manutenção que potencializou o aparecimento das patologias.
\end{abstract}

Palavras-chave: Manifestações Patológicas, Manutenção, Inspeção Visual

\section{Introdução}

A engenharia está em constante transformação, e sempre buscando se adaptar aos novos desafios e descobertas, tantos por novos materiais usados, mas também pelas novas técnicas e exigências normativas, contudo nem sempre é possível atingir de forma satisfatória o padrão de excelência, seja por mão de obra não qualificada, seja erros construtivos dentre outros fatores que contribuem para a deterioração precoce (SOUZA; RIPPER, 1998).

O objetivo deste trabalho foi analisar as causas e origens das principais manifestações patológicas em 5 (cinco) Escolas Municipais de Jaboatão dos Guararapes - PE, bem como a analise do estado de conservação das estruturas das escolas. As escolas estão à uma distância média de aproximadamente $658 \mathrm{~m}$ da orla marítima.

Segundo Gomide (2012), a manutenção é uma série de medidas que devem ser tomadas para manter a estrutura ou até mesmo reverter o quadro em alguns pontos, para que a estrutura retorne ao desempenho satisfatório, podendo atender as necessidades de seus beneficiários. Para Sousa e colaboradores (2016), quando não se tem a manutenção adequada em uma edificação surgem às manifestações patológicas que podem ter diferentes origens, mas todas apresentam algum dano, que pode ser apenas estético quanto estrutural. 
Este trabalho é relevante pois entender quais são as principais manifestações patológicas em edificações escolares é importante para previnir novas construções escolares quanto à esteas frequentes patologias Além disto as medidas de manutenção e adequação da infraestrutura são fundamentais para que as atividades escolares aconteçam da melhor forma possível, para isso é necessário que os ambientes da escola se encontrem em boas condições de uso e conservação para atingir o resultado preposto do ensino (ALMEIDA, 2009).

\section{Referencial Teorico}

\subsection{Manifestações Patológicas}

As manifestações patológicas podem se expressar por meio da umidade no meio, trincas e fissuras na estrutura de maneira geral, bolor decorrente do excesso continuo de umidade, corrosão das armaduras e o surgimento de vegetação.

\subsubsection{Umidade}

De acordo com Parisi Jonov, et al. (2013), a umidade é uma manifestação patológica das mais prejudiciais em construções durante sua utilização, e pode ter diversas causas que influenciam seu aparecimento, entre elas, o solo, fatores climáticos, o tempo de construção, associado a erros construtivos e falta de manutenção.

\subsubsection{Trincas e Fissuras}

Segundo Corsini (2010), as trincas e fissuras podem ocorrer tanto na alvenaria quanto nas peças de concreto, surgindo não apenas na parte estrutural, mas também, nos revestimentos da edificação, ten do como suas principais causas: (a) Uso em desacordo com o projeto, em casos de cargas acima do permitido; (b) Variação de temperatura, principalmente na interligação de materiais diferentes; (c) Retração e expansão, por vezes causadas por excesso de cimento na composição; (d) Deformação de elementos da estrutura de concreto armado; (e) Recalque de fundações, principalmente nos casos em que acontece em forma diferencial; (f) Reações químicas, que resultam em outras manifestações patológicas como, por exemplo, a reação álcalis e agregado e (g) Detalhes construtivos, como ausência de juntas.

Para Barreto et al (2016) as fissuras podem ter $1 \mathrm{~mm}$ ou menos, e aparece na face das construções e não causa distanciamento significativo de placas. Em contrapartida as trincas aparecem na estrutura da placa e provoca separação entre elas, e tem aberturas superiores a $1 \mathrm{~mm}$. O gretamento pode ser visto como varias fissuras interligadas, com um formato que lembra ninhos de aranhas, e com aberturas menores que $1 \mathrm{~mm}$ na superfície das placas. Não sendo solucionadas, a longo prazo podem influenciar no aparecimento de diversos tipos de patologias tendo como exemplo, a presença de trincas que pode dar início ao deslocamento de placas cerâmicas e ao aparecimento de eflorescências (MONTEIRO, 2016).

\subsubsection{Bolor}

Segundo Dias et al (2004), em casos de chuvas duradouras, o excesso de umidade dificulta a secagem e a constante absorção devido a umidade relativa do ar estar alta, nessas circunstâncias a concentração de água elevada, favorece a formação de bolor e manchas superficiais nas construções.

\subsubsection{Corrosão de armaduras}

A corrosão de armaduras por sua vez trata da degradação das barras de aço presentes no concreto, que acontece quando a barreira física (cobrimento) que protege as armaduras e a porosidade do concreto permite a entrada de agentes agressivos dando início ao processo de corrosão (MEIRA, 2017). Essa patologia acarreta desde a perda de seção da área de aço chegando ao ponto de causar fissuração bem como desplacamento do revestimento, causado pelo efeito expansivo da corrosão e podendo também causar manchas na superfície (SOARES et al, 2015).

O método de corrosão de armaduras pode acontecer de duas maneiras, pela corrosão química ou oxidação que se caracteriza por uma baixa velocidade de corrosão que ocorre devido a uma reação gás-metal, ou seja, pelo contato do ar atmosférico com o aço, formando compostos de óxido de ferro (SANTOS, 2015). Além disso, a corrosão eletroquímica ou eletrolítica também conhecida por corrosão catódica, este processo 
acontece em meio aquoso devido à diferença de potencial entre dois pontos da armadura, o ânodo e o cátodo. Esta reação funciona como uma pilha eletrolítica, e se torna o mais perigoso processo de corrosão na construção civil (GENTIL, 2011). Todavia estas reações são expansivas, criando tensões inesperadas no concreto provocando sua fissuração. Dentre os possíveis fatores que ocasionam a corrosão estão o recobrimento das armaduras abaixo dos valores recomendados pela Associação Brasileira de Normas Técnicas (ABNT), deficiência de cura do concreto, alto fator água/cimento e o ataque de agentes agressivos como sulfatos e cloretos (SANTOS, 2015).

\subsubsection{Vegetação}

O surgimento de vegetação se dá pela concentração de sujeira que são acumuladas em alguns pontos das edificações que junto com insolação, está associada também a concentração de umidade por vezes causada por vazamentos contribuem para o mantimento das plantas, fatores que apontam possível ausência de manutenção (GARCEZ, 2009). Assim, vegetações dessa natureza causam danos variados, de acordo com sua estatura, tamanho da copa que contribui no sombreamento das áreas externas, favorecendo um acumula de umidade e a sua expansão (GARCEZ, 2009).

\section{Metodologia}

Trata-se estudo descritivo com abordagem qualitativa que partiu da análise estrutural através de inspeções visuais e das fotografias tiradas em 3 visitas a 5 escolas municipais da cidade de Jaboatão dos Guararapes-PE todas próximas a orla marítima, com a finalidade de obter as informações necessárias para a identificação de patologias, suas causas e possíveis soluções com base em trabalhos anteriores sobre patologia em construções. Fachim (2005) salienta a observação como ponto inicial em uma pesquisa, de modo a permitir um contato com o objeto observado, advindo do resultado e esforço de pesquisas empíricas.

\subsection{Local de Estudo de caso}

O município do Jaboatão dos Guararapes fica localizado no litoral do Estado de Pernambuco. Com uma área territorial de 256 quilômetros quadrados. Ao Norte da capital Recife e o município de São Lourenço da Mata, ao Sul com o Cabo de Santo Agostinho, a Leste com o Oceano Atlântico e a Oeste com Moreno. Está inserida na Região Metropolitana do Recife (RMR). População: 644.620 com uma área territorial: 256,073 km² (IBGE - 2010).

O clima é quente e úmido, com maior incidência de chuvas em outono - inverno. A temperatura média ao ano é de 28 graus centígrados. O perfil do relevo, do leste para o oeste, é composto por uma Planície Costeira formada por depósitos fluviais e marinhos. Seu litoral é composto pelas praias de Piedade, Candeias e Barra de Jangada todas com o nome dos bairros a que pertencem. $O$ estudo foi realizado em setembro de $2018 \mathrm{e}$ concentrou-se em analisar cinco escolas municipais da cidade de Jaboatão, dos bairros litorâneos.O município de Jaboatão dos Guararapes tem atualmente 92 escolas municipais, sendo 15 escolas municipais localizadas nos bairros de Barra de Jangada, Candeias e Piedade.

\subsection{Descrição das Escolas estudadas}

Foram selecionadas 5 escolas municipais das 15 localizadas nos bairros litorâneos de Jaboatão dos Guararapes, dividido nos seguintes bairros: escolas " $A$ " e "B" no bairro de Barra de Jangada, escola " $C$ " e " $D$ " no bairro de Candeias e a escola " $E$ " no bairro de Piedade

As escolas " $B$ ", " $C$ ", " $D$ " e " $E$ " receberam manutenção em seus telhados nos últimos seis meses segundo os diretores, além dessas escolas citadas terem mais de trinta anos em conversa com os mesmos foi constato que não há reforma preventiva nessas escolas. Na figura 1 Abaixo podemos observar a localização das escolas e sua distância para a orla marítima. 
Figura 1 - Localização das Escolas

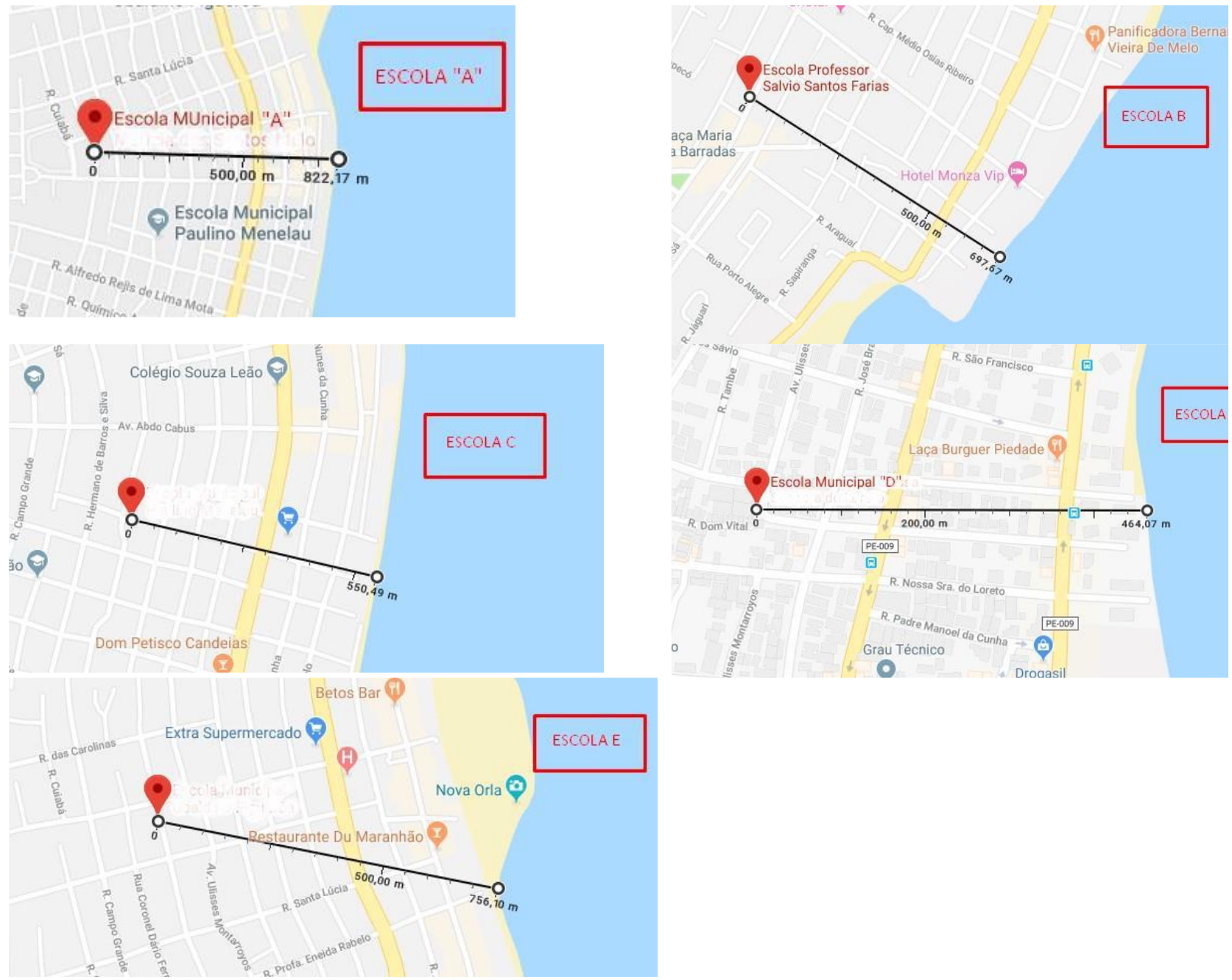

Fonte: Google Maps, 2018

Nas visitas realizadas aos colégios, foram obtidos registros fotográficos de todos os ambientes internos aos limites que demarcam os colégios, entre eles estão: salas de aula, banheiros, cozinha, auditório, biblioteca, laboratórios, refeitório, secretaria, diretoria, almoxarifado, quadra. Foram realizados registros fotográficos das manifestações patológicas encontradas e a análise dos dados consistiu a priori quantificar todas as manifestações patológicas semelhantes em cada escola, classificando-as em: umidade; bolor; trincas ou fissuras; corrosão de armadura; e vegetação. Em seguida, com as informações coletadas, estudou-se caso a caso, buscando-se verificar as possíveis causas, possíveis soluções ou recomendações dos problemas encontrados.

\section{Resultados e Discussões}

A Patologia das construções é uma ciência responsável por estudar as origens, produtos, e mecanismos que geram problemas e acabam por deteriorar a estrutura. Partindo deste princípio, obter o conhecimento sobre manifestações patológicas possibilita a escolha da intervenção ideal para cada situação (ARIVABENE, 2015). Deste modo as escolas " $A$ ", " $B$ " e " $C$ " não apresentaram manifestações patológicas de corrosão de armaduras, somente a escola " $A$ " encontra-se em bom estado de uso e conservação apresentando uma pequena incidência de umidade e bolor na caixa d'água. As escolas " $D$ " e " $E$ " apresentaram todas as patologias analisadas nesse estudo de caso, conforme consta a (Tabela 1). 
Tabela 1: Manifestações patológicas incidentes nas escolas

\begin{tabular}{l|ccccc}
$\begin{array}{l}\text { E.M. Jaboatão } \\
\text { dos Guararapes }\end{array}$ & Umidade & Bolor & $\begin{array}{c}\text { Tricas ou } \\
\text { Fissuras }\end{array}$ & $\begin{array}{c}\text { Corrosão de } \\
\text { Armaduras }\end{array}$ & Vegetação \\
\hline Escola "A" & $\mathrm{X}$ & $\mathrm{X}$ & $\mathrm{X}$ & . & . \\
Escola "B" & $\mathrm{X}$ & $\mathrm{X}$ & $\mathrm{X}$ & . & X \\
Escola "C" & $\mathrm{X}$ & $\mathrm{X}$ & $\mathrm{X}$ & $\mathrm{X}$ & $\mathrm{X}$ \\
Escola "D" & $\mathrm{X}$ & $\mathrm{X}$ & $\mathrm{X}$ & $\mathrm{X}$ & $\mathrm{X}$ \\
Escola "E" & $\mathrm{X}$ & $\mathrm{X}$ & $\mathrm{X}$ &
\end{tabular}

Fonte: Autores

Como mostra a (Tabela 2) é possível constatar que 117 ocorrências de manifestações patológicas nas escolas. Somente as escolas "B" e " $D$ " apresentando corrosão de armaduras representando 4\% da quantidade de ocorrências analisadas.

Tabela 2: Percentagem de ocorrência em relação ao total de escolas e de ocorrências.

\begin{tabular}{l|cccc|}
$\begin{array}{l}\text { E.M. Jaboatão } \\
\text { dos Guararapes }\end{array}$ & $\begin{array}{c}\text { Quantidade de } \\
\text { escolas }\end{array}$ & $\%$ & $\begin{array}{c}\text { Quantidade de } \\
\text { Ocorrências }\end{array}$ & $\%$ \\
\hline Umidade & 5 & $100 \%$ & 55 & $47 \%$ \\
Bolor & 5 & $100 \%$ & 27 & $16 \%$ \\
Trincas e Fissuras & 4 & $80 \%$ & 19 & $4 \%$ \\
Corrosão de Armaduras & 2 & $40 \%$ & 4 & $10 \%$ \\
Vegetação & 4 & $80 \%$ & 12 &
\end{tabular}

Fonte: Autores

No consolidado (Tabela 2) fica evidenciado que 70\% das ocorrências são de umidade e bolor decorrentes de $100 \%$ das escolas analisadas. Somente a escola " $A$ " não havia realizado recentemente reforma do telhado de sua unidade e apesar disso estava em bom estado por ser uma escola com menos de 10 anos de uso em comparação com as outras com mais de 30 anos.

Gráfico 1- Consolidado de quantidade total de ocorrências.

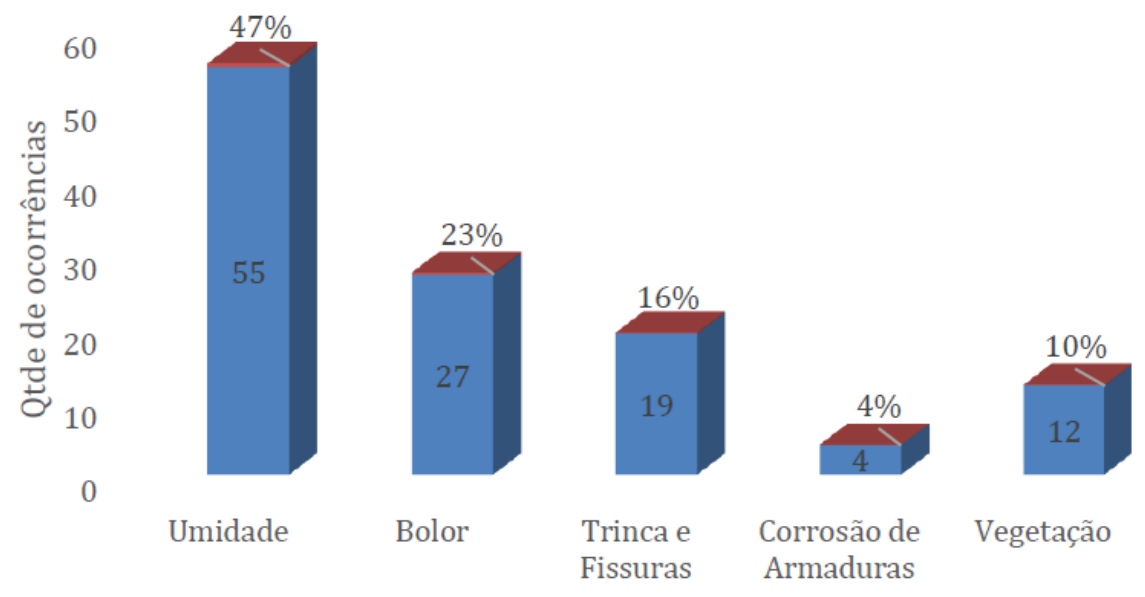

Fonte: Autores 


\subsection{Umidade}

Na figura dois podemos observar a presença de umidade nas escolas estudadas.

Figura 2: Presença de umidade no teto da sala de aula nas escolas estudadas

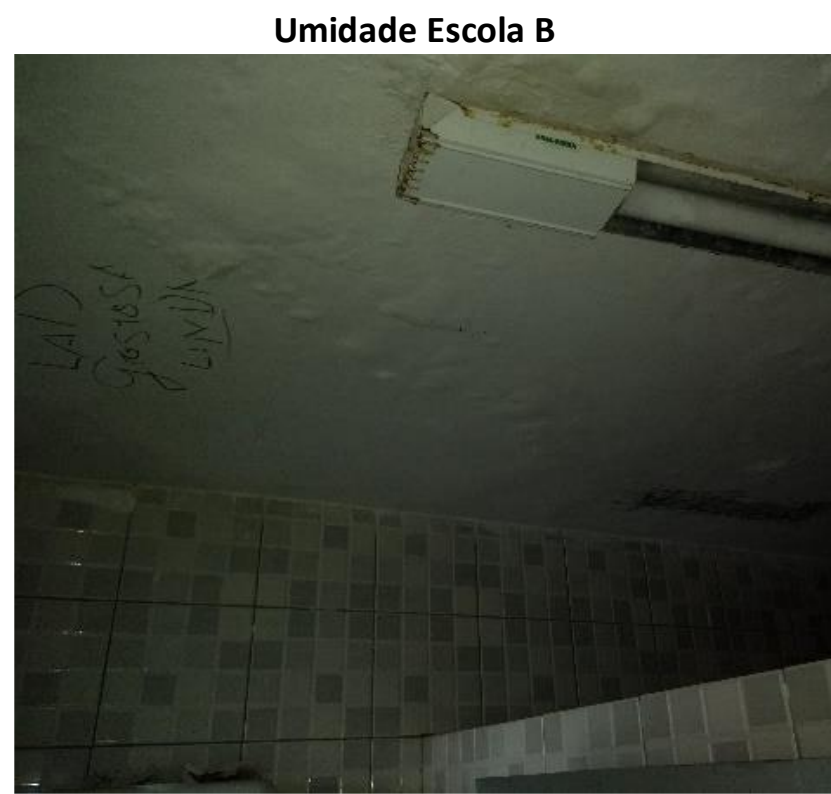

Umidade Escola D
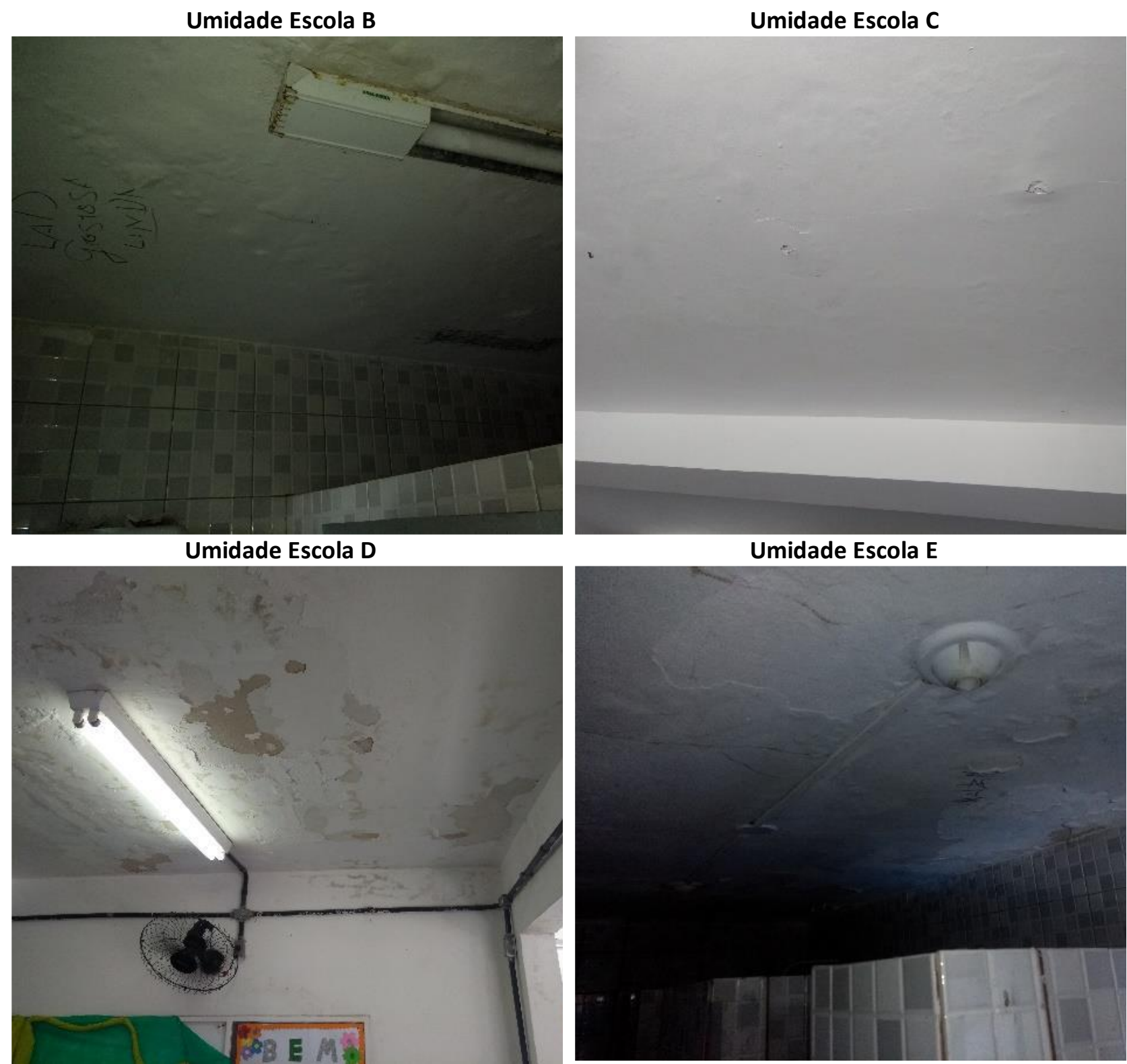

Umidade Escola E

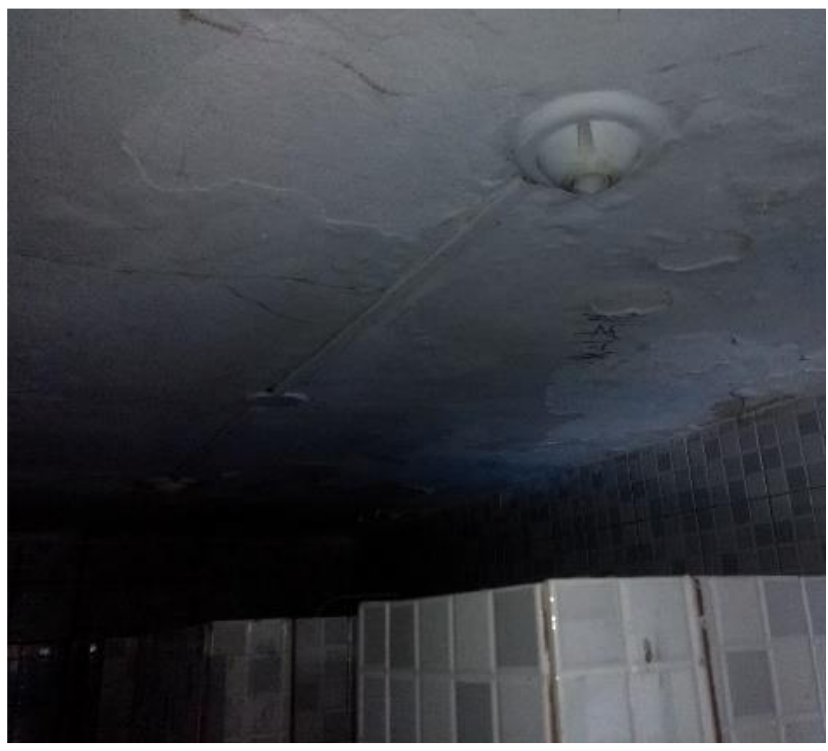

Fonte: Autores

Não foi possível o acesso para avaliação dos telhados, segundo os diretores das escolas " $B$ ", " $C$ ", " $D$ " e " $E$, foram realizados reparos recentemente dos telhados". Todas tinham umidade em suas dependências em salas de aula e banheiros, somente a escola estava em bom estado com umidade na caixa d'água.

Como solução recomenda-se a verifica ção detalhada dos telhados para possível impermeabilização, troca do reboco e nova pintura. 


\subsection{Bolor}

Evidenciou-se bolor mais nas partes externas das estruturas como pode ser observado na (Figura 3), sendo necessário a identificação dos pontos e as causas das infiltrações, manutenção e troca das calhas, limpeza das superfícies e pintura preventiva.

Figura 3: Presença de bolor nas escolas
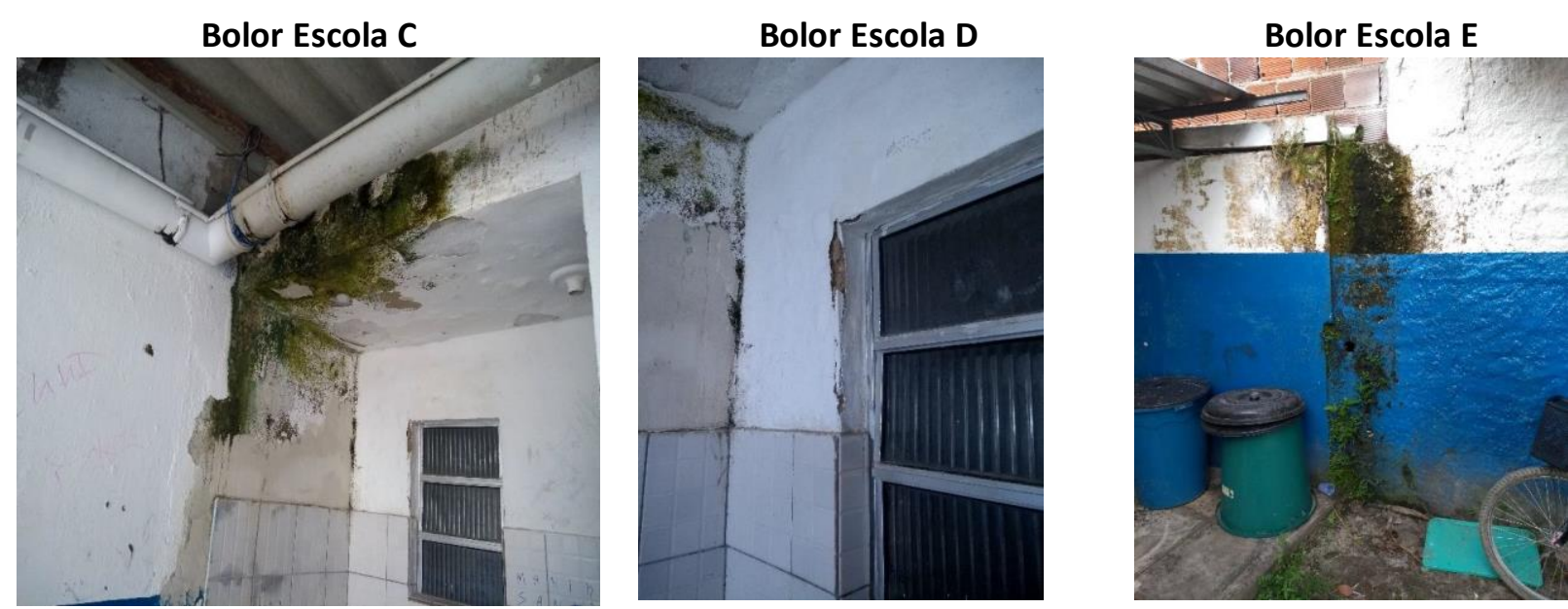

Fonte: Autores

\section{3 - Trincas e Fissuras}

As fissuras presentes nos elementos estruturais (vigas e pilares) de forma paralela à armadura como vemos na (Figura 4), são indicativas do processo de corrosão da armadura, ou de dimensionamento incorreto do elemento. Uma análise mais detalhada deve ser realizada, para que se possa ter um diagnóstico mais completo que sirva de base para os projetos de restauração dessas estruturas.

Figura 4: Trincas e Fissuras encontradas nas Edificações

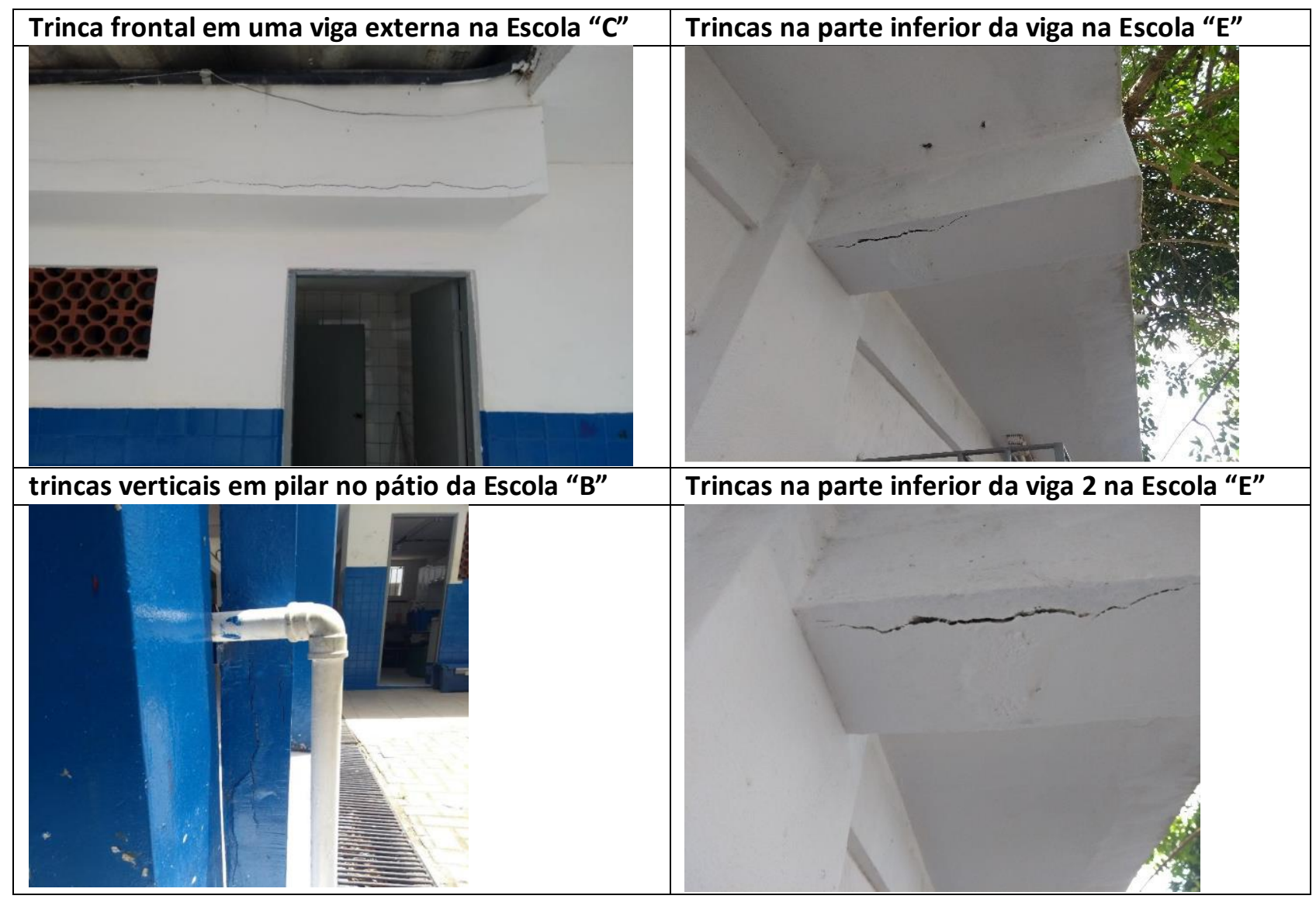

Fonte: Autores 


\section{4 - Corrosão das Armaduras}

As escolas analisadas situam-se em média à $700 \mathrm{~m}$ da orla, deveria ser sido adotado no projeto a cobertura de grau de agressividade 3 (cobrimento para laje de $35 \mathrm{~mm}$ e pilar $40 \mathrm{~mm}$ ) foi observado na (Figura 5) que não foi atendida nem o grau de agressividade 2 (cobrimento de laje de $25 \mathrm{~mm}$ e pilar de $30 \mathrm{~mm}$ ) nas estruturas analisadas conforme foto acima. Segundo Andrade (1992), é recomendado a eliminação do concreto contaminado ou deteriorado, devendo ser removido até que se encontre o concreto em bom estado. Além disso, é preciso eliminar o concreto $1 \mathrm{a} 2 \mathrm{~cm}$ por detrás das armaduras corroídas com o objetivo de permitir um bom acesso para a limpeza adequada dos produtos de corrosão. Esse espaço permite também o correto preenchimento dos vazios ao redor das barras pelo material de reparo.

\section{Figura 5 - Ocorrência de Corrosão das Armaduras nas Escolas}

\begin{tabular}{|c|c|}
\hline $\begin{array}{c}\text { Corrosão na laje acima do portão de acesso ao } \\
\text { pátio na Escola "E" }\end{array}$ & $\begin{array}{c}\text { Corrosão na armadura do pilar na saída do pátio } \\
\text { na Escola "D" }\end{array}$ \\
\hline &
\end{tabular}

\section{Fonte: Autores}

\subsection{Vegetação}

A vegetação mostrada na (Figura 6) pode interferir no desempenho estrutural da edificação, através de suas raízes e também no entupimento de calhas e outros condutores de águas pluviais através da perda de folhas. Recomenda-se, limpeza das calhas e retirada da vegetação e tratamento da superfície afetada.

Figura 6 - Ocorrência de Vegetação nas Escolas Estudadas

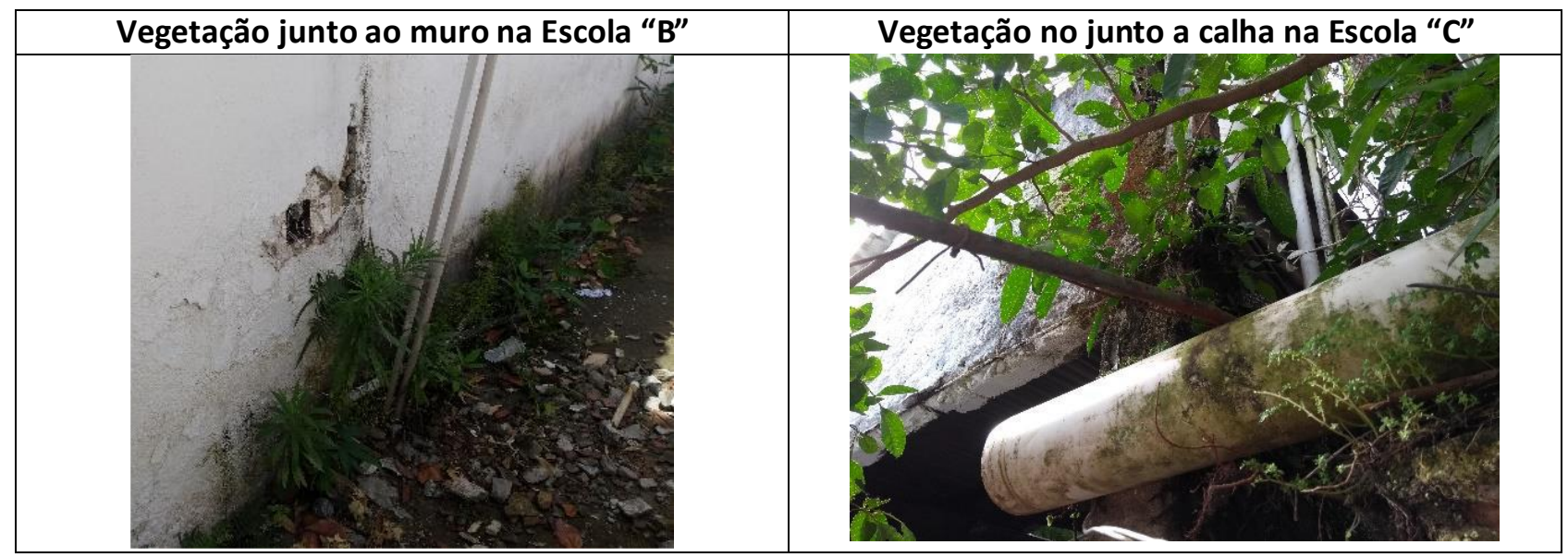

Fonte: Autores 


\section{Conclusões}

Através desse estudo foi possível identificar diversas patologias nas escolas em questão, em $100 \%$ das escolas foi possível a identificação de umidade e bolor, totalizando $70 \%$ de todas ocorrências encontradas na inspeção. As manifestações patológicas encontradas nas escolas quase sempre estavam associadas à presença de água, principalmente por meio de pontos de infiltração,

A atenção a localização que a obra será submetida e o atendimento as normas brasileiras quanto ao processo construtivo evitariam muitas dessas ocorrências, evitando assim submeter crianças a ambientes nocivos.

É necessário de uma avaliação detalhada periódica nas escolas visitadas para melhor avaliação dos problemas e manutenção dos locais identificados, posteriormente a realização de uma cultura de manutenção preventiva, para evitar intervenções futuras no caso do agravamento, a fim de garantir edificações mais duráveis e seguras, melhor atendendo as expectativas de suas funcionalidades para a sociedade.

\section{REFERÊNCIAS}

ALMEIDA, D. Manutenção do patrimônio escolar. Nova Escola. São Paulo, 2ed., 2009.

ANDRADE, C. Manual para Diagnóstico de obras deterioradas por corrosão de armaduras. São Paulo, Pini 1992.

ARIVABENE, A.C. Patologias em estruturas de concreto armado estudo de caso. Revista On-line IPOG Especialize. Vitória, 2015.

BARRETO, L.; RAMOS, J. L. M.; BERENGUER, R. A.; CARNEIRO, F. L.; NASCIMENTO,E.C; MONTEIRO, E.C.B. Análises das manifestações patológica sem estruturas de concreto armado de subestações de energia elétrica (subestação Joairam). In: 2o Congresso brasileiro de patologia das construções (CBPAT-2016), 2016, Belém - PA. Anais... Belém-PA, 2016.

CORSINI, R. Projetos: Trinca ou fissura? Revista Téchne. Julho, 2010. Disponível em: http://techne.pini.com.br/engenharia-civil/160/trinca-ou-fissura-como-se-originam-quais-os-tipos-2854881.aspx. Acesso em: outubro de 2018.

DIAS, J. F.; TOFFOLI, S. M.; AGOPYAN, V. Absorção de telhas cerâmicas vermelhas. In: Congresso brasileiro de cerâmica, 48, Curitiba, 2004. Anais...Curitiba: 2004.

FACHIM, O Fundamentos de Metodologia. 4. ed. São Paulo: Saraiva, 2005.

GARCEZ, Nuno Feliciano da Silva. Sistema de inspeção e diagnóstico de revestimentos exteriores de coberturas inclinadas. 2009. 204f. Dissertação (Mestrado Integrado em Engenharia de Aeródromos) Instituto Superior Técnico da Universidade Técnica de Lisboa. Lisboa, 2009.

GENTIL, V. Corrosão.6. ed. São Paulo, 2011.

HISTÓRIA DA CIDADE: Um breve histórico do município de "Yapoatan. Conheça Jaboatão, Jaboatão dos Guararapes, 23 de out. de 2018. Disponível em - «http://jaboatao.pe.gov.br/historia-da-cidade/〉. Acesso em 23 de out. de 2018.

MAPS: google maps, Jaboatão dos Guararapes, 23 de out. de 2018. Disponível em 〈https://www.google.com.br/maps〉. Acesso em 23 de out. de 2018.

MEIRA, G. R. Corrosão de armaduras em estruturas de concreto. João Pessoa, 2017.

MONTEIRO, E. Notas de aula da pós-graduação de inspeção, manutenção e

Recuperação de estruturas na Universidade de Pernambuco. Recife, 2016.

GOMIDE, A. J. Prova Pericial no Direito Imobiliário. São Paulo: PINI, 2012.

PARISI JONOV, C.M.; NASCIMENTO, N.O.; PAULO E SILVA, A. Avaliação de danos às edificações causados por inundações e obtenção dos custos de recuperação. Ambiente construído. Porto Alegre, 2013.

SANTOS, C. F. Patologia de estruturas de concreto armado. Santa Maria, 2014.

SOARES, A. P. F. et al. Corrosão em Armaduras de Concreto. Ciências exatas e tecnológicas. Maceió, 2015. SOUZA, V. C.; RIPPER, T. Patologia, recuperação e reforço de estruturas de concreto. São Paulo: Pini, 1998. SOUSA, N. M.; FILHO, W. B.S.; SILVA, G. F.; RIBEIRO, W. L. B. Manifestações

Patológicas nas Escolas de Ensino Fundamental e Médio do Município de Monteiro - PB. In: Congresso Brasileiro de Patologia das Construções, 2016, Belém do Pará. Anais... São Leopoldo: Casa Leiria, 2016. THOMAZ, E. Trincas em edifícios: causas, prevenção e recuperação. 2. ed. São Paulo: Pini, 2013. 